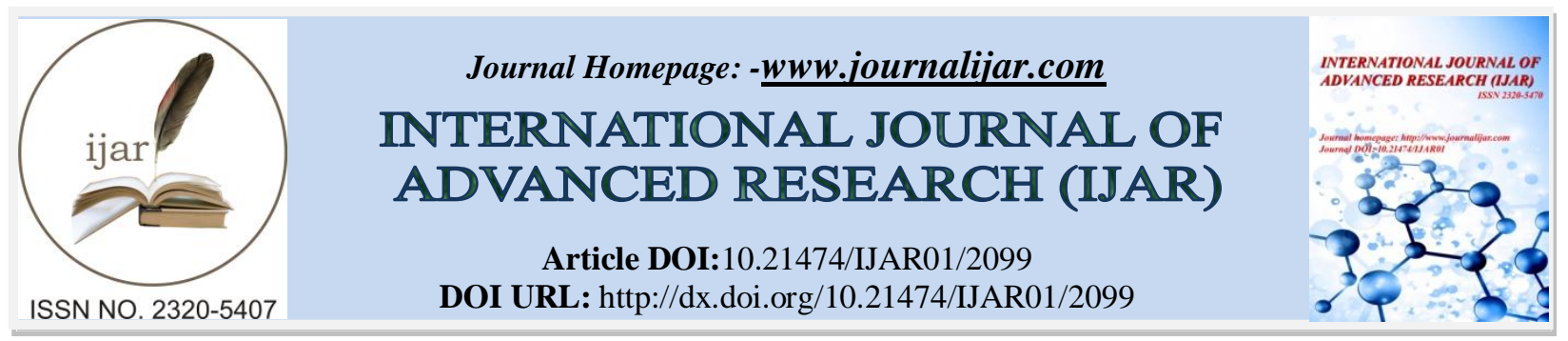

RESEARCH ARTICLE

\title{
SHAPING THE FEMALE IMAGE IN THE DOMESTIC SPHERE: LOOKING AT HEBREW MAGAZINES' ADS.
}

Shahar Marnin-Distelfeld.

\section{Manuscript Info}

Abstract

Manuscript History

Received: 24 September 2016

Final Accepted: 26 October 2016

Published: November 2016

Copy Right, IJAR, 2016,. All rights reserved.

\section{Introduction:-}

This research paper focuses on advertising strategies used repeatedly in ads for domestic products in Hebrew magazines ad manuals of pre-state Israel. These strategies combined verbal texts with visual images to promote a specific product, and by doing so, they also constructed a representation of the 'ideal' homemaker and mother. Advertisements featuring representations of homemaker and mother first appeared in the Hebrew press of the 1920s (Marnin-Distelfeld, 2016: 199). During the 1930s and the 1940s, local ads for domestic products were added and the popular press in pre-state Israel started to resemble its overseas prototypes.

This article will examine strategies of shaping representations of women occurring in ads for home products and it is based on a comprehensive research of about one hundred and fifty ads, which appeared in dailies, in women's magazines and in manuals published in Hebrew, over the three decades prior to the establishment of the state of Israel, in 1948. The period of the new Hebrew settlement in pre-state Israel, beginning with the first immigration to the establishment of Israel, is perceived in modern Jewish history as a time of local Hebrew culture crystallization (Even-Zohar, 1980: 165-166; Ben-Porat, 1999:49). The appearance of ads in the press and in popular literature reflected a process of cultural flowering, characterized by increasing population and rapid economic growth (Helman, 2007: 11). Immigration waves from central Europe in the 1930s made a crucial contribution to the development of economy, society, and culture (Gelbar, 1990:385). The field of advertising marched along with industry and manufacturing, as suppliers of bourgeois consumerism culture, centering in the city of Tel-Aviv. In the 1940s, following World War II, many industrial plants were set up and thus the product and advertising market expanded, too (Helman, 2007:23).

Until the 1920's, Hebrew press ads lacked illustrations almost entirely and contained detailed verbal text specifying the product's virtues (Marnin-Distelfeld, 2016: 200). Later, in the 1920's, the first illustrated ads emerged many of which featuring women's representations. Like the products, the ads, too, were imported and placed in the Hebrew press with their text translated into Hebrew. The decision to include these in this research corpus was based on the notion that they were verbally adapted for Hebrew speaking readers albeit visually highly similar, and sometimes identical to the original ads. In addition, this decision was also based on the marketing principle by which ads embody the essence of accepted values and norms of the society where they appear, to generate situations with which the target audience can easily identify (Liebes \& Talmon, 2004: 318; Morris, 2006: 13). 
In this article, three main strategies are to be explored through a gendered perspective: advertisements based on alerting and threatening the woman, advertisements that were designed as a women's conversation, intimate and gossip-like, and those depicting a male figure, usually a scientist or a physician, as an authoritarian figure. These strategies will be analyzed with the assumption that they were chosen based on world views prevalent in the Hebrew society in the land of Israel, whether consciously or un-consciously. This analysis will aim to extract meanings and massages inherent in the ads as a reflection of both their makers and the target audience they were aimed at. (Bartal, 2013: 137-147).

\section{Methodology:-}

The ads researched have been collected from the three major dailies- Davar, Haaretz and Hatzofe, from women's magazines and manuals published in Hebrew between 1920 and 1948. Choosing these three dailies stemmed from the wish to create an ideologically wide corpus: each daily belonged to a different political stream: Davar - The socialistic sector, Haaretz - The liberal sector, and Hazofe - The religious Zionist sector. The dailies were systematically sampled - three months each year, so that a month reviewed in one year was not scanned the following year, so as to create a reliable sample reflecting the seasons, holidays, political events, etc. As to women's magazines - all published during that period were fully reviewed. Manuals included consisted both of major Yishuv institutions' publications and books published by private authors or commercial publishers. All manuals relevant to the household and female topics found in archives of those years were also reviewed.

After categorizing the ads to three main strategies, a few were selected as an example of each strategy, and these are the ones presented in the article. A methodology was chosen combining content analysis focusing on semiotic theories and models following Roland Barthes's definition of the ad as a mini-narrative, a kind of a meaningful sign sequence (Barthes, 2006: 71-72). John Fiske followed Vladimir Prop to recognize three key pointsof the narrative's plot: breaking of the balance thus creating instability, the protagonist fighting the forces of evil and resuming the balance by resolving the conflict (Fiske, 1990: 136-137). The narrative ideology, which is shaped by the ad's strategy, exists within the conflict of imbalance and its resolution, and through identifying the values involved in it (Todorov, 1977: 10-11). The point of imbalance will be fixed by a subject or hero/heroine, whose job is to reinstall order. Based on these principles, Algirdas Julien Greimas developed his Actant Model which contains six agents: the sender, the object, the subject/hero, the antagonist/enemy/opponent, the helper/assistant/ and the recipient (Hebert, 2006: 1-3). The actants are the elements functioning within the plot and can even constitute abstract concepts. The narrative plot is motivated by a sender, who appoints a hero, who, in turn, through obtaining the object, is supposed to resume order. On his/her way, he/she will meet both helpers and opponents whom he/she will overcome until finally achieving the desired object. There are three axes at the basis of each narrative: the axis of desire - where the hero acts to achieve the object, the axis of power - where the helper and opponent act, and finally the axis of knowledge - the one lying between the sender and the recipient.

The content analysis is based on a series of questions targeting both verbal text and image. The indices referring to the visual images were inspired by Ervin Goffman's work, while studying ads from a gender-oriented point of view (First, 2001; Bell \& Milic, 2002; Vestergaard \& Schroder, 2004; Kang, 1997; Linder, 2004). The indices included the image of a woman as a central figure (the heroin): Is this representation narrative-like and repeated, or concise? Is the heroin active or passive? The woman's position: standing or seated? Where is she positioned - near a table, in a chair, on the floor, in a bed? Job division of man and woman: are the two being displayed next to one another in the same scene? What jobs are done by the woman and which by the man? The relationships among family members: how close is the woman to her children, to her husband? How is the relationship between husband and wife depicted regarding look, touch, etc.? Does the body appear whole or partial? Does the woman touch feminine objects or parts of her own body? Interaction between the spectator and the woman: Does the woman look straight at the spectator or does not look at him/her at all?

The relationship between the verbal text and the visual image was examined regarding the location of the headline, the slogan, the main text, and the illustration. Are the main text and the illustration a completion to one another? Do they offer a "preferred reading" of the ad? (Fiske, 1990: 110-111) Are they different from one another in their way of addressing the reader? (Martinec\& Salaway, 2005: 337-340). The verbal text was studied regarding its verbal level - whether it was standard, up-standard, or sub-standard language (Zeevi, 2010 b: 92). The tone of the text was probed by checking the selected words and terms and the manner of address - imperative or second person. 


\section{Discussion and Findings:-}

Characteristics of the Domestic Product Ad of Pre-State Israel:-

During the 1920s, domestic products ads mostly contained verbal text, describing the product in details, without an illustration. There were only few illustrated ads at that time, all imported from Western magazines. Those products included food, health, hygiene, and clothing items. In the 1930s, two local Israeli companies, 'Shemen' and 'Yizhar', dominated the domestic products market and ads, and their goods gradually filled the magazines for several decades to come. Aside from their ads, many foreign ads were also in display, promoting products imported to pre-state Israel by local companies. During the 1940s, this tendency continued, with an elaboration of ads - both local and foreign. They all shared a similar style of ads, in both form and content, and centered on an image of the homemaker as a well-groomed matron, wearing a dress and apron, high-hill shoos, sometimes with her face madeup.

The ads were designed using four elements: a bold headline, a central visual image, a detailed verbal text, and a slogan accompanied by the logo or a small illustration representing the company or the product. It seems that the local advertisers were influenced by their colleagues abroad while shaping their ads, reflecting a general adaptation of style and content of Western magazines by Israeli ones (Narunsky-Laden, 2007: 605). Ads from pre-state Israel were characterized by loaded text formats, a feature to be continued for at least one decade ahead (Zeevi, $2010 \mathrm{~b}$ : 90). The large amount of text, occupying most part of the ad's composition, was usually focused on the advantages of the product but also played a significant role in introducing new products to the newly developing market of the Yishuv (Zeevi, 2010 a: 223). However, in this article I shall argue, that this application was not completely rational, as is sometimes argued about early ads of that time, but also emotional. In many cases, the ad was applying to the potential buyer, a woman, whose decision to buy a certain product would gain her values and not only material goods. Many domestic ads focused on the homemaker aiming to direct her to become the 'ideal' Hebrew woman. The three strategies combined rational and emotional tendencies in order to convey ideological massages to the 'ideal' homemaker and mother. In many ads, the visual image got the central attention, featuring the woman's characteristics and behavior as an efficient homemaker buying and using the promoted product.

\section{The Alerting Strategy:-}

Many domestic products ads chose to portray uncomfortable situations, dominated by a threatening tone towards a woman figure. This type of ads included all areas of domesticity, with an illustration of a homemaker or mother depicted as a central image. The text referred to the woman in imperative form, whereas the illustration showed a frightened expression, and an apprehensive gesture. In some cases, the illustration featured a child /children, while the woman figure was absent altogether.

In a 'Shemen' company ad for 'Meged' cooking oil (fig. 1), typically edited with four elements - headline, illustration, detailed text, and a slogan (or name of the product), we encounter the alerting strategy. The upper headline is bold and is directed at the homemaker in imperative: "Do not buy with your eyes shut!" Below a homemaker is depicted going shopping blindfolded with a piece of cloth. She is holding a purse in her left hand and scouting her way in the right. The covered eyes imply uncertainty, an un-known path that the homemaker is supposed to walk along. She seems lost. The covered eyes also indicate that someone was trying to fail or mislead her, maybe the shopkeeper shown as a black background figure juxtaposed with her figure. This person mentioned by the text, tried to sell her a lower quality and cheaper cooking oil. The long text includes five paragraphs, four of them referring directly to the homemaker in second person, while only one of them describes the oil in question. The text tells her how she should behave during war times - be extra-cautious and avoid fake products, (called "meziot" in Hebrew), which flooded the market of the Yishuv in those days. The text uses standard language explaining to the woman that: "You are not a chemist; therefore you cannot check the quality of this product...but after a while the stomach will indicate what the eye could not tell at shopping time..." The assumption that the woman is not a chemist was based on a perception which excluded women from the world of knowledge and science. They were associated with physical sensations which did not always help them manage their domestic space. The paragraph ends in a threatening tone: "... and the small saving of buying the cheap oil would cost you a lot - the health of your family!"

The woman is described as the person responsible for shopping for the house, but here she is depicted as incapable of doing so successfully. At the bottom of the ad appears a small illustration of a tiny male chef, personified as the product itself (fig. 1, right). 


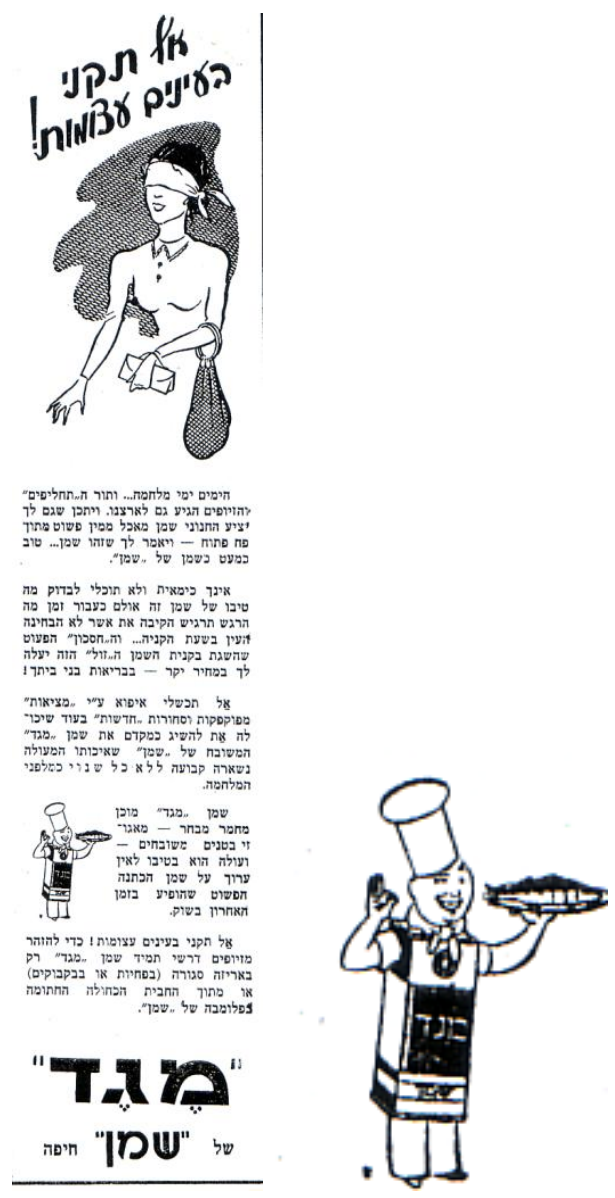

Fig. 1: -Ad for 'Meged' cooking oil. Olam Ha'Isha, 10, 1940, p.14. (right: a detail enlarged).

A chef is holding a tray, full of food cooked with 'Meged' oil while on his box-like apron the product brand name is written. Placing the homemaker's hesitant representation together with the chef's satisfied image contributes to constructing contradictory values of an incompetent homemaker versus a successful chef, an unsecure woman versus a confident man, as also stressed by the text.

The situation depicted in this ad is what Goffman defines as "The clown body" (Goffman, 1979: 50; First, 2001: 28) meaning female figures described in ridicules poses, indicating their embarrassment. (Doring \& Poschl, 2006: 176). What is understood by this example is that the incapable, intimidated and humiliated homemaker was perceived by the Yishuv society, where the ad was created and viewed, as normative, and thus served as a selling image.

The alerting strategy was most popular in ads for products connected to mothering. Mothering during the Mandate period required caution as the health system was making its first steps, there were scarcely any medicines in hand and baby mortality rates were high (Schwartz \& Shchori-Rubin, 2001: 253-254). In an ad for a hygiene product 'Bebe Shopman's' (fig. 2) the text focuses on addressing the mother, and the illustration is of a baby lying in a bed, alone. In the upper part a naked baby is depicted lying down, with a disturbed expression on his face. The caption reads, "The baby is sweating - don't be afraid, Mother! Use Bebe Shopman's ". The use of the imperative formand that of formal letters prove the authority which the advertiser assumes over the absent mother. Both the illustration and the text, help convey the message that a sweating baby causes fear in the mother. A semiotic analysis of the narrative suggests that an unbalanced situation is created here by a sweating baby and a terrified mother. The balance will be resumed only when the baby stops sweating and the mother will consequently calm down. The representation of the mother, visually absent, appears through the verbal text addressing her as a fragile entity. This shows the mother's low status in the eyes of the advertiser. The unprotected baby described without his mother, not only proves his mother incapable but also threatens all potential inefficient mothers. 


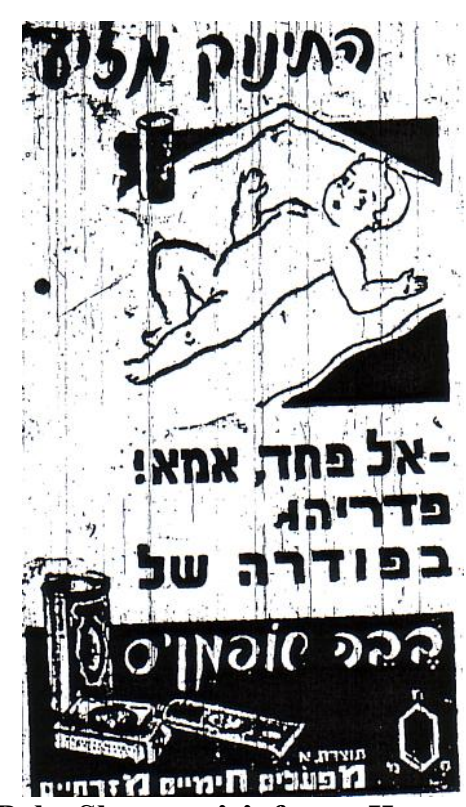

Fig. 2:- Ad for 'Bebe Shopman's'. from: Haaretz (4.9. 1933), p. 3.

The alerting strategy was in use in many ads for cleaning products, as in a 'Glaxo' ad for a healthy brand of milk. (fig. 3, left). A mother is depicted protecting her child from a demonized insect or germ. Many hands and arms are trying to stop the personified insect, which can talk and his spoken sentences occupy most of the ad: "I am stronger", "I hide in the milk", "I am a TB germ". If we use the actant model, the insect is the opponent fighting against the representatives of the 'good' world - science and scientific products, as well as those who will follow them, like the mother. The mother is the heroin trying to protect her child, with the assistance of 'Glaxo', which helps build bones and provides protection from the evil parasite. "'Glaxo' is TB-germ free milk providing health and energy to children, and happiness to mothers". The objects of desire are healthy children and happy mothers. Logically, what the inscription means is that healthy children make happy mothers. This is probably why the mother is depicted with her long arm dramatically raised to block the insect which obliquely flies towards her. The oblique line divides the ad into two triangles, but more significantly intensifies the attack threatening the mother holding her child. The fact that the illustration of the container itself is right by the mother and close to the product's graphic brand name, suggests that the mother was successful at protecting her child, and brings the narrative to its relieving ending. The emotional notion of the advertiser is more dominant here than the rational one.

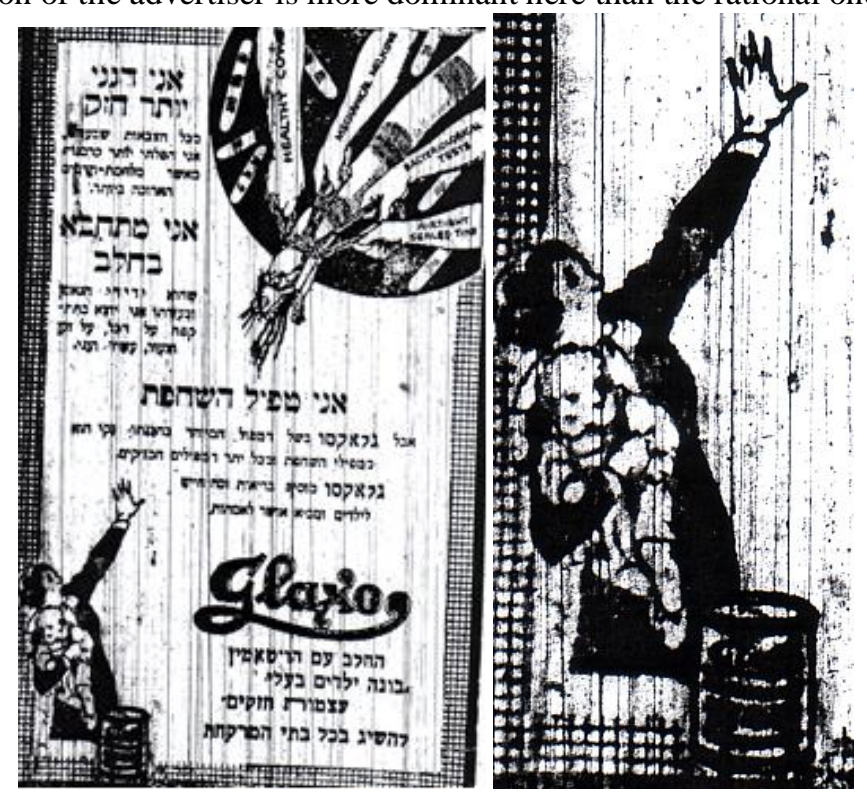

Fig. 3:- Ad to 'Glaxo'. From: Haaretz (30.11.1928), p. 4. (right: a detail) 


\section{Women's-Chat Strategy:-}

A woman visiting her female friend at her house, or two mothers meeting each other while strolling their babies were situations quite popular in advertisements of the first half of the $20^{\text {th }}$ century. Creating a setting of women's domesticity contributed to define household chores as exclusively feminine. Women's chats often focused on efficient shopping, which was perceived as the ideal national behavior of the homemaker, and on good mothering in times of shortage (Marnin-Distelfeld, 2016: 206). It is striking to discover the popularity of the strategy of women'schat in ads while reading editorial articles and motherhood manuals which repeatedly expressed their doubts about women's ability to successfully advise other women. Women's-chat strategy embodied an inner contradiction: on the one hand, the feminine territory, where women could share their experience, had gained them empowerment; but on the other hand, the way those women were described and the tone of their conversation, implied a critical attitude, as if one woman needed to prove her friend wrong, to promote a certain product. Also, there was always a glimpse of righteousness in the way one woman treated her mate. That was, in my opinion, the power of this strategy, which is defined as "gossip ads" (Vestergaard \& Schroder, 2004: 414). In gossiping, there is sometimes a sense of surprise and provocation, and in "gossip ads" the heroin is typically surprises by her friend advising her to improve her performance by using a specific product. In the following examples, we meet two women discussing a domestic issue, regarding either the household or mothering.

In an ad to 'Menora' laundry soap (fig. 4) we watch a homemaker hanging an undergarment while another woman gets close to her, approaching her with an embarrassing question, "Didn't you know, Mrs. Levi?!" The direct application, the use of both question mark and exclamation mark and her surprised expression - all convey a clear message to the reader: This homemaker is un aware of a significant household act - the use of the promoted product, to improve her domestic performance. These are all connotative signs constructing the homemaker's inferior status in the eyes of the reader. Intimidation and even humiliation serve as popular appealing strategies to attract audiences in media today (Weimann, Cohen \& Bar-Sinai, 2009: 1-2) but in Mandate pre-state Israel this strategy was exclusively in use with female figures.

The unequal point in the narrative is the homemaker's use of the 'wrong' laundry soap, ignoring the values of 'Menora'. These values are highlighted in the body of the ad: The relationship between the verbal text and the visual one is striking and can be seen in the three parts of the ad: the upper part, in which the women's chat is depicted, the middle part, where the virtues of the product are given, and the bottom part with the brand logo and the image of the candelabrum ("Menorah" in Hebrew). Following the actant model, the homemaker is the heroinembarking on a journey to achieve balance in her house. The women's chat functions as the starting point of the narrative, destabilizing the homemaker's domestic work. In the middle part, verbal and visual texts are integrated, with the latter exemplifying the former. The ad is set as a maze guiding the homemaker and the potential buyers to use 'Menora'. The products' advantages are described: reliability for many years, scientific quality, and its being 'kosher'. Another term is used to define the user of the product as "green" which is extremely ahead of time being an environmental feature. Following the actant model, the friend as a helper, representing the sender, which here is the company itself, and hegemonic society in general. Additional helpers are the chemist responsible for the quality of the soap and the physician measuring the child's height - both representing scientific authority. One would expect the scientific elements to also be expressed in the name or logo of the product, but 'Shemen' company chose to entitle their laundry soap 'Menora' with the image of the candelabrum, which arouses a historical connotation to the Jewish symbol of the temple menorah and its sacred oil. This menorah had burned on olive oil, same oil of which the soap was made. The use of this oil, helps define the homemaker as national. We understand that both the product and its promoter, the female friend, function as signifiers of an expected national domestic behavior. 


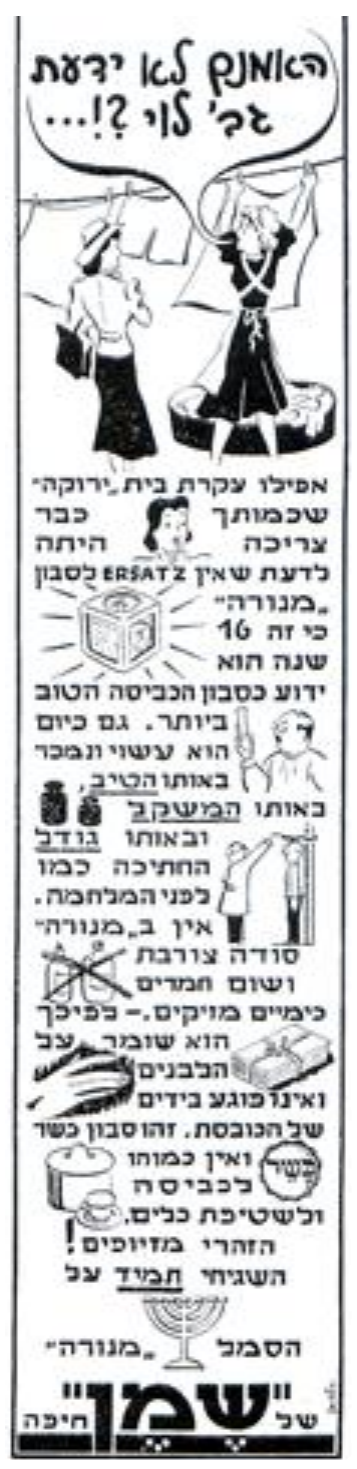

Fig. 4:- 'Menora' ad, a product of 'Shemen'. From Olam Ha'Isha, May 1941, 21, p. 4.

Women's chat as an advertising strategy was most common regarding mothers discussing baby and children food, hygiene, and clothing products. The foreign ads were influential for local advertisers who adopted this strategy and developed it in different variations. In some cases, the talk was simply a starting point for an elaborated situation, in others -women's chat went all along the ad, an episode which comes to a closure when the two women are actively talking it through. In a foreign ad for 'Postum' (fig. 5, left), and in a local ad promoting 'Kessem', (fig. 5, right) we see two women chatting in the presence of a child. The 'Postum' ad is designed as a three-episode story: In the upper part, we see an unsatisfied toddler raising his arm to show his frustration while his mother shares her despair with a friend. At this moment of imbalance, the friend approaches the mother, astonished, "What happened to your child, Jonah? He was never like that?" This meaningful question embodies not only a true friendly concern, but also conveys an implication of the mother being helpless and clueless as to her child's problem. The next episode finds the friend advising the mother to substitute the coffee she had used, with 'Postum'. The last episode, depicted at the bottom part of the ad, takes place "after three weeks", when the two women meet each other again, outside the house, down the street or in a park (there is a tree on the right-hand side). The hats they are wearing designate their being in the context of the public sphere, where norms and social values are practiced. The mother reports on an improvement in her child's behavior, his grumpiness has disappeared, when her friend is listening, smiling in satisfaction, a 'Postum' container set next to her. 
Desirable balance has been resumed thanks to the good advice from the friend, who functions as a helper in this narrative. Above her figure in the bottom part, the product's virtues are listed, compared to the damaging caffeine. The intimate chat between the two women, shown in the text above their images, conveys a sense of openness and honesty - two elements which strengthen the credibility of the advertised product. The process that is described in the ad is a three-week apprentice journey aiming to guide the mother how to become a better one. The continuous women's chat becomes an educational agent targeted at shaping an 'ideal' mother, directed by the advertiser, and more generally by prominent norms and perceptions of that time.

In a 'Kessem' ad, we can find the ambivalence of feminine empowerment mixed with women's rivalry, which characterizes many of the ads using the strategy of women's chat. Direct speech of the women is bold and noticeable at first sight. The expressions "How Sweet" and "Between you and I" create a sense of intimacy which aims to attract women readers and to strengthen their emotional engagement with the ad. The women are chatting about a baby's clean clothes. The friend is asking the mother how come she could afford to buy new clothes in times of war (World War II) and the mother explains she didn't buy new clothes but simply used 'Kessem' laundry powder. The surprising response given by the assertive mother, instantly renders her an 'ideal' homemaker, not wasting money when she is supposed to save it. She is portrayed as a modest and rational woman, negating her friend's implied accusation. The accusing tone of her friend is exactly the gossip-like element which made the strategy of women'schat appealing for both advertisers and consumers.

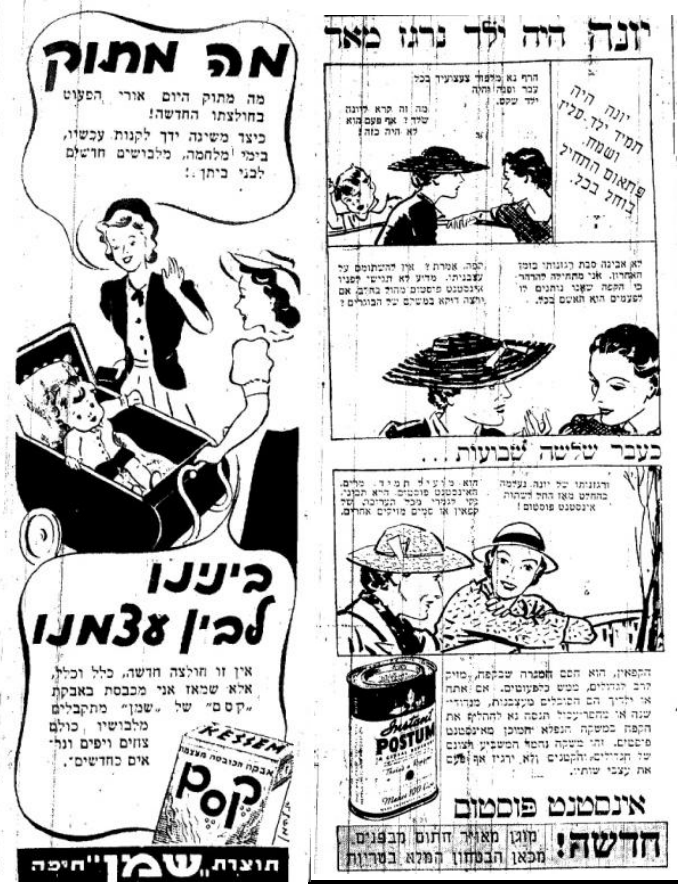

Fig. 5:- 'Postum' ad. From: Haaretz(8.4.1938), p. 4. (left) 'Kessem' ad. From: Haaretz(17.9.1942) p. 4 (right).

The Strategy of Scientific Male Authority Versus the Woman:-

Most domestic products' ads focused on situations featuring household chores performed by homemakers and mothers, but surprisingly enough, some of them chose to portray a male figure as the main character, while the text was meant for women. The man may sometimes be the husband, representing a superior authority over his wife, but mostly he is a representative of the scientific world. This fact reflected the role scientific ideology played in Western societies, in the first half of the $20^{\text {th }}$ century being the ultimate solution to any obstacle, including those in the domestic sphere. Western women magazines of that time promoted "experts" advice on domestic activities, delegitimizing women who trusted their instincts or other women's experience (Foss, 2010: 307). The scientific ideology was evident in ads, where the ingredients of each product were described in details. Women were depicted as lacking the scientific knowledge, which stressed their incapability of performing well at home. Many researches have emphasized the correlation between patriarchal normative situations where men were the source of professionalism and authority versus women being dependent on them and thus - the use of this hierarchy in advertisements (Goffman, 1979:15 ;Doring \& Poschl, 2006:173 ;Bell \& Milic, 2002: 204). 


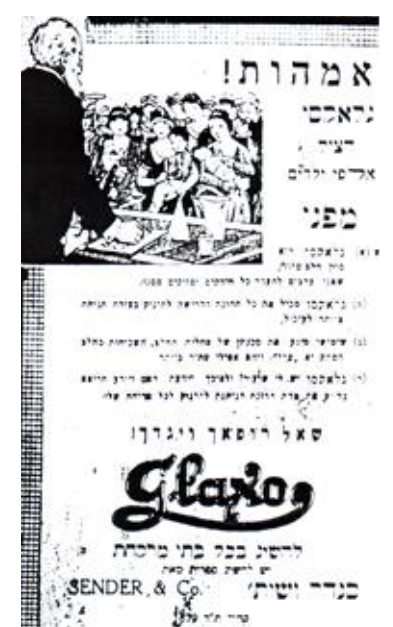

Fig. 6: 'Glaxo' ad. From Haaretz (20.6.1927), p. 4.

In a 'Glaxo' ad, stands the authoritarian bearded figure of a male physician in front of a crowd of young mothers holding their babies (fig. 6). Following the actant model, the mothers are heroines while the doctor is a helper. The 'Glaxo' drink is another helper and the object of desire is healthy children. Although he is a single figure and the mothers are many, he is depicted as the knowledgeable one and they are the listeners and learners. Standing on a podium, he is positioned as the authority over the women, legitimately alerting them about 'Glaxo' "saving thousands of children", as the inscription reads. His addressing the women, calling, "Mothers!" with an exclamation mark, renders his words dramatic and solemn, thus imposing a tone of fear. This gender hierarchy engulfed in a frightening atmosphere, stressed by the women's worried faces, was used to intrigue the reader's curiosity. This strategy probably appealed to foreign advertisers and consumers given that this hierarchy was acceptable and normal in Western societies of that time. Apparently, it fitted the Hebrew society as well (Hirsch, 2014).

In an ad for hygienic pads 'Haviva' and for women's hygienic belts 'Nurit', the illustration occupies most of the ad space. (fig. 7). A bearded, good- looking male physician is seen pointing with his arm towards the products in question, which are exclusively feminine. Like the figure in the previous example, he is authoritarian, but this time, instead of facing the women he is facing the reader. There is no woman figure in sight but the woman is represented in three different ways: the text reads "Use only this product" in the feminine imperative form in Hebrew. The name of the two products are also feminine - 'Haviva' is an adjective meaning 'darling', and 'Nurit' is a name of an Israeli wild flower- buttercup - which has a feminine form and was highly popular then. Finally, on the product's box there is an illustration of a woman with a head cover, looking like a nurse or a nun. Visually, women are almost absent from the ad but nonetheless, they are implicitly represented, being the objects of reference as the ones to use the above products.

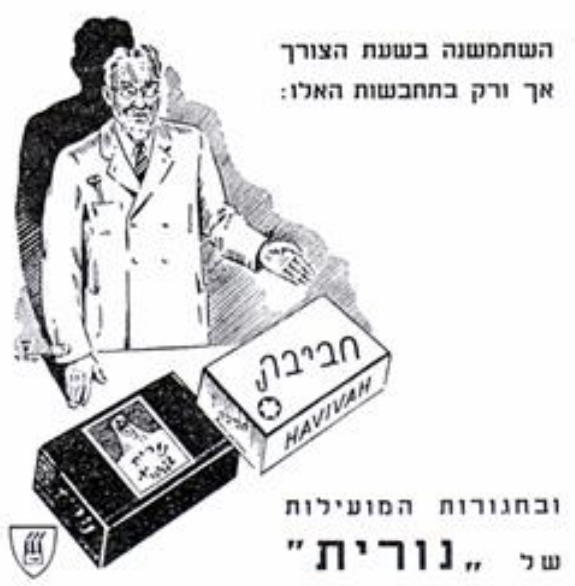

Fig. 7:- Ad for 'Haviva' and 'Nurit'. From Y. Smilanski (1940), All For Women, p. 12. 


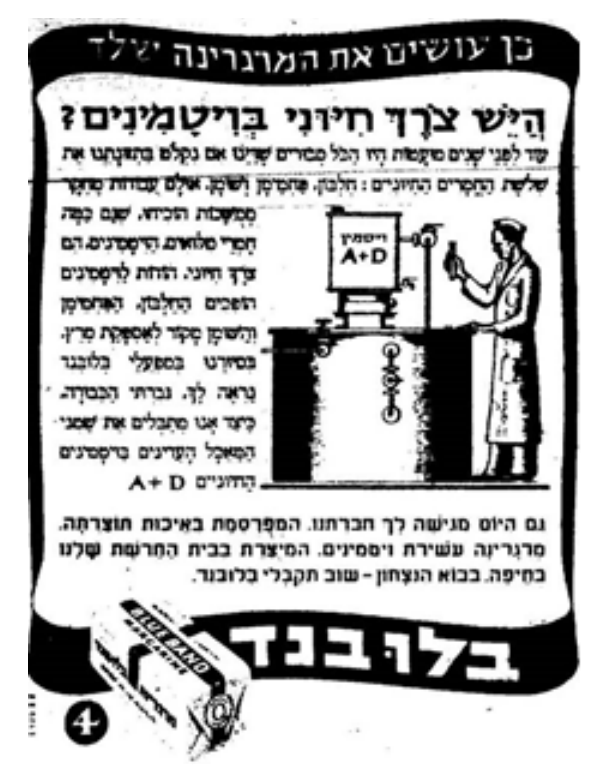

Fig. 8:- 'Bluband' ad. From Hatzofe (4.6.1944), p. 3.

In a 'Bluband' ad, our eye is captured by an illustration of a man, dressed in a chemist's robe, working in a laboratory (fig. 8). Two captions frame the ad in its upper edge, most of the body of the ad is occupied by a detailed text and illustration, and at the bottom - the brand name is written in bold printed letters aside the product image. The very upper caption "This is how we make your margarine" is not punctuated and therefore could be read as both female and male order in Hebrew. The lower caption "Are vitamins necessary?" leads to the main text explaining the scientific importance of vitamins to the human body. The text directly addresses the homemaker, reading, "In our factory tour, you will be shown, Madame, how we add vitamins to the delicate oils that we use". The last lines of the text promise the homemaker that when the war ends, the product will return to its original form and content, offering her a temporary version of it resulting wartime scarcity of supplies. The division between the scientific world represented by the male chemist, manufacturing the product, and the homemaker being the object the text is referring to, was perceived as socially acceptable; therefore, the advertiser could freely adopt it as a promoting strategy.

\section{Conclusion:-}

This qualitative research focused on three strategies implicated in advertisements for domestic products in Hebrew magazines and manuals from pre-state Israel. The strategies were examined from a gendered point of view to decode perceptions towards the status of women: advertisements based on alerting the woman, advertisements designed as a women's chat, intimate and gossip-like, and advertisements depicting a male figure, a scientist, or a physician, as an authoritarian figure confronting a woman. What all three strategies had in common was constructing an inferior representation of a woman versus a superior representation of a man. This correlates with many ads research studies which found stereotypical images of lower status of women compared to stereotypical images of higher status of men (Morris, 2006:17). It is possible, though, that women's representations in ads tended to exaggeration and were not a pure reflection of reality. This strategy, used to promote certain products, does not seem to weaken our findings but rather explores the legitimate way of thinking about gender in society of that time. Controversial situations regarding domestic life shown in ads, and strategies the advertisers used, contributed to reinforce perceptions of men and women in society (Lemish, 2000: 541-542).

The three strategies emphasized the emotional attitude over the rationale one, while giving the voice of the advertiser - being that always a man - the authority to judge the homemaker and the mother, and to demand her to improve her capability. The emotional character of the ads, conveyed by the relationship between verbal text and visual images, was most dominant in these ads. This conclusion contradicts a previous one regarding early ads, being more rational and product focusing (Zeevi, 2010 b: 92). 
Analyzing the alerting strategy explored a frightened, threatened and a clueless representation of the homemaker and mother. A sweating baby or a dangerous insect hiding in the milk described as extremely threatening for the woman. Even shopping, which was her everyday chore, portrayed as too complicated for the homemaker to manage. A standard language and a direct addressing to the woman and in addition an illustration of her in embarrassing poses - contributed to construct an inferior representation of the woman. The advertiser functioned as the sender, calling the woman to go on a journey in which she would resume balance to her home and family, but this process focused on a threatened figure of a woman, which was probably perceived as normal.

The women's chat strategy was another way to shape an invaluable representation of a woman. While the ideology of domesticity defined the house as a feminine domain, the women's chat exposed a crack in this female solidarity. A woman-friend getting into another woman's territory was found ambivalent: sharing domestic experience could be supportive but also offensive. Women's chat strategy based its appeal on being both cheering and nasty, or "gossip-like". The advice a woman got from her friend seemed helpful but also proved the woman's misbehaving. Using intimate spoken-language expressions and setting the ad as a continuous episode narrative, with an illustration of two women close to one another created a private space in which the reader was invited to enter, often as a critical judge.

Another strategy was that posing the scientific man versus the unknowledgeable woman. The authority of man and science were portrayed as crucial for the homemaker and mother in order to handle domestic chores. The verbal text addressed the woman in second person but visually she was absent. The hierarchy of scientific male professionals and women in need of their knowledge was perceived as a normative and therefore beneficial even when the products were purely feminine.

The ideal Hebrew homemaker image was always described as ambivalent; on the one hand, advertisers assigned women with the responsibility for managing the domestic space properly, and portrayed them as dominant in the domestic space. While on the other hand, they were denied both the authority and the capability to appropriately carry out their tasks. The woman's figure remained fragile and indecisive, and at times even scorned and humiliated compared to male images. This ambivalence reflected a similar attitude towards women within society: Hebrew women in the Yishuv have not gained equality and were forced to struggle for their status (Bernstein, 2001: 116). The ads adopted and followed a conservative approach, which reinforced gender boundaries, held by the social cultural hegemony in pre-state Israel.

\section{Notes:-}

1. Bartal, O. (2013): The Story of a Japanese Ad Poster: Interactive Methodology for Studying Advertising Images. D. Arieli-Horovitz, O. Barthal and N. Meiri-Dan (eds.), Protocollage 2013 Visual Writing: Methodologies in Visual Culture Studies, The-Aviv: Resling: pp. 137-147. (in Hebrew)

2. Barthes, R. (2006): Foundations of Semiology (trans. By Anver Lahav), Tel-Aviv: Resling. (in Hebrew)

3. Bell, P. and Milic M. (2002): Goffman's Gender Advertisements Revisited: combining content analysis with semiotic analysis, Visual Communication, Vol 1 (2): 203-222.

4. Ben-Porat, A. (1999): Where Are Those Bourgeois? The History of Israeli Bourgeoisie, Jerusalem: Magnes. (in Hebrew)

5. Bernstein D. S. (2001): Voices of the Hard Core - Women of the Second Aliya. Atzmon, Y. (ed.), Will You Listen to My Voice? Representations of Women in Israeli Culture. Tel Aviv: Hakibbutz Hameuchad, pp. 116133 (in Hebrew)

6. Doring, N. \& S. Poschl. (2006): Images of Men and Women in Mobile Phone Advertisements: A Content Analysis of Advertisements for Mobile Communication Systems in Selected Popular Magazines. Sex Roles, 55: 173-185.

7. Even-Zohar, I. (1980): The Growth and Crystallization of a Native Local Hebrew Culture in Eretz Israel, 18821948, Cathedra, 16: 165-189 (in Hebrew)

8. First, A. (2001): Women as Objects: Images of Men and Women in the Israeli Ad, Alma, 10: 26-30. (in Hebrew)

9. Fiske, J. (1990): Introduction to Communication Studies, London: Routledge.

10. Foss, K. A. (2010): Perpetuating 'Scientific Motherhood': Infant Feeding Discourse in Parents Magazines, 1930-2007, Women \& Health, 50 (3):297-311.

11. Gelbar, Y. (1990): A New Homeland: The Immigration and Absorption of Central European Jews 1933-1948, Jerusalem: Yad Ben-Zvi and Leo Beck Institute. (in Hebrew) 
12. Goffman, E. (1979): Gender Advertisements, New York: Harper \& Row, Publishers, Inc.

13. Hebert, L. (2006): The Actantial Model, in L. Hebert (dir.), Signo, Rimouski (Quebec), http://www.signosemio.com.

14. Helman, A. (2007): Urban Culture in 1920s and 1930s Tel Aviv, Haifa: The University of Haifa. (in Hebrew)

15. Hirsch, D. (2014): 'We Are Here to Bring the West': Hygiene Education and Culture Building in the Jewish Society of Mandate Palestine, The Ben-Gurion Research Institute for the Study of Israel and Zionism Publishing House (in Hebrew)

16. Kang, M. E. (1997): The Portrayal of women's images in magazines advertisements: Goffman's gender analysis revisited. Sex Roles, 37: 979-996.

17. Lemish, D. (2000): 'If you are not there, you do not exist' - The ad as a window to the Israeli Society. H. Hertzog (ed.). A Society through the Mirror. Tel Aviv University, pp 539-559. (in Hebrew)

18. Liebes, T. and M. Talmon (eds.) (2004): Communication as Culture, Tel-Aviv: The Open University. (in Hebrew)

19. Lindner, K. (2004): Images of women in general interest and fashion magazine advertisements from 1955 to 2002. Sex Roles, 51: 409-420.

20. Marnin-Distelfeld S. (2016): Home-Maker and Mother Representations in Advertisements of Pre-State Israel. International Journal of Humanities and Social Science, 6 (3): 199-211.

21. Martinec, R. and Salway, A. (2005): A system for image-text relations in new (and old) media, Visual Communication 4(3): 337-371.

22. Morris, K. P. (2006): Gender in Print Advertisements: A Snapshot of Representations from Around World. Media Report to Women, 34 (3): 13-20.

23. Narunsky-Laden S. (2007): Consumer Magazines in South Africa and Israel, Journalism Studies, 8(4): 595-612.

24. Schwartz, S. \& Z. Shchori-Rubin, (2001): Women Organizations for Mothers and Children in Eretz Yisrael: Hadassa, Hebrew Women Organization and Wizo establishing 'Tipat Chalav' Stations, 1913-1948. S. Margalit, R. Krak and G. Hazan-Rokem (eds.). New Hebrew Women: Women in the Yishuv and in Zionism from a Gendered Perspective. Jerusalem: Yad Ben-Zvi, pp. 248-269. (in Hebrew)

25. Todorov, T. (1977): The Poetics of Prose, Blackwell.

26. Vestergaard T. and K. Schroder (2004): Strategies of Address: Gender and Status. T. Liebes and M. Talmon (eds.) Communication as Culture, Tel-Aviv, The Open University, pp. 397-431. (in Hebrew)

27. Weimann, G. Y. Cohen and I. Bar-Sinai (2009): A 'Humiliated Star': Examining the correlation between humiliation in reality shows and their entertainment quality. Misgarot Media, 3: 1-26. (in Hebrew)

28. Zeevi I. (2010 a): Between 'Kitan Clothing Manufacturers' and 'Kitan\&Co': Linguistic Characteristics of Past and Present Magazine Ads, Hebrew as a Living language, H, pp. 219-238. (in Hebrew)

29. Zeevi I. (2010 b): 'The Loss of Simplicity': The Rhetoric of the Israeli Printed Magazines in the First Decade and in the Current One - A Comparative Examination. Misgarot Media, 5: 83-112. (in Hebrew) 